\title{
Who Are We Now? Organizational Identity and Generational Change in a Community College
}

\author{
Rene Ramos \\ Miami Dade College \\ $300 \mathrm{NE} 2^{\text {nd }}$ Avenue \\ Miami, FL, 33132 \\ Sunddip Panesar Aguilar \\ University of St. Augustine \\ 1 St. Augustine Blvd \\ St. Augustine, FL, 32086 \\ USA \\ Erick Aguilar \\ iQuality \\ Jacksonville, FL
}

\begin{abstract}
Community colleges are complex institutions with wide-ranging goals and missions. The problem is there may be perceived generational differences in the sustainability of the organizational identity (OI) of these increasingly important institutions. Research questions examined (a) the revelatory power of institutional archives vis-à-vis OI, (b) intentional and unintentional actions taken by leaders which shape OI, (c) processes affecting the evolution of organizational memory, and $(d)$ the impact of organizational membership on OI. The study used an intrinsic case study design to examine archival documents and interviews of millennial generation community college leaders at a large community college. The subject institution's archives were shown to be a rich source of OI, yielding 10 core themes. Interviews with 30 millennial generation managers mirrored most of these themes, and yielded additional OI themes, suggesting $O I$ is being reinforced and gradually transformed by the new generation of leaders. The study informed recommendations and implications for leadership, including mentoring programs to promote knowledge transfer between older and younger organizational leaders. The study also contributes to the subject institution's strategic planning process and may assist other institutions contending with workforce generational change.
\end{abstract}

Keywords: Organizational identity, Change leadership, Organizational memory, Social identity theory,

\section{Introduction}

Community colleges in the United States and elsewhere have come to be seen as multipurpose institutions with expansive, welcoming missions aimed at bringing higher education and benefits to citizens (Cohen \& Brawer, 2013). These institutions educate close to half of the undergraduate student population in the United States (U.S.), with enrollments of 7.4 million credit students and 5 million noncredit students (Chase-Mayoral, 2017). As such, community colleges have increasingly been called upon to perform multiple social services not provided by or expected of secondary or regular tertiary educational institutions, and their identity claims are often expressed with the vocabulary of social justice and change (Chase-Mayoral, 2017; Cohen \& Brawer, 2013). In the U.S., where educational costs are continually increasing, free community college tuition has entered the national political debate; the concept was included in the Democratic Party's national platform during the 2016 presidential election (Palmadessa, 2017). These educational organizations are evolving and being transformed by new and emerging leadership cadres and warrant further study.

With a workforce participation level of 53.5 million persons, the millennial generation cohort born from 1981 to 1997 emerged to represent the largest share of the U.S. workforce in 2015 (Fry, 2015). Research on millennials' attitudes toward the workplace, and in particular, toward public service in areas such as government and education, has revealed important similarities and differences from those of preceding generations (Fry, 2015). There is a lack of studies on the millennial generation's attitudes and behaviors in the educational sector as the cohort becomes the largest component of the workforce, and its members assume leadership positions at schools, colleges, and universities. 
The demographic transition toward millennial generation workforce dominance, combined with the growing social importance of community colleges and similar institutions, presents opportunities for focused study on the millennial generation's attitudes and impact on community college leadership.

\section{Problem Statement}

There may be perceived generational differences in the sustainability of OI, which need to be identified and better understood. As educational organizations grow and change, succeeding leadership cohorts may become disconnected from original elements of OI. The problem may be acute for organizations founded in the 20th century, before the advent of online systems and other innovations which have challenged the original missions, operations, and delivery methods of educational institutions. In particular, social media and other technological innovations, which coincide with the rise of millennials in the administrative ranks may be implicated in communication-style changes which, in turn, affect millennials' perceptions of OI (Ravasi, 2016). Building on research, which shows how OI provides the foundational elements for projected organizational image (Ravasi, 2016), examinations of differences in OI perception between founding 20th century institutional leaders and rising millennial generation leaders are important for understanding the evolution and future of community colleges.

There is little research on the nature of OI processes in higher educational institutions, and even less research which also includes a focus on generational change of management at community colleges (Ravasi, 2016).

\section{Purpose of the Study}

The purpose of this qualitative intrinsic case study was to analyze the origin, evolution, and current state of OI as experienced by leaders in a community college, focusing on the impact of generational change. The geographic focus of the study was the area served by MDC, which is in the greater Miami, Florida, area. The college serves and employs a large, dynamic, and ethnically diverse population, and therefore, an extended study of its OI processes could potentially increase knowledge for practitioners at similar institutions. The study was approved by and shared with the subject organization's institutional research and human resources (HR) departments, with the desired effect of informing the institution's thought and future internal research on OI and leadership issues, and succession planning.

\section{Theoretical Framework}

The origin, evolution, and status of the institution's OI was analyzed through the prism of social identity theory (Tajfel \& Turner, 1986). Social identity theory is the dominant learning theory and theoretical model in the OI literature. Tajfel and Turner (1986) described a set of psychological connections between in-group identification of members and groups. In a reversal of the widely held view of actors as shapers of group identity, intergroup conflict and the way it shapes organizations was promoted as an important influence on self-identification of group members, with the group ultimately exerting more influence on the individual than vice versa (Tajfel \& Turner, 1986). Organizations are in competition with each other for resources, and often come to achieve status and self-image based on the outcome of conflict and competition. Subsequently, members of organizations gradually self-ascribe impressions of enhanced status and image characteristics (Tajfel \& Turner, 1986). Application of these findings to the qualitative intrinsic case study shed light on how and why organizational members became attached to social groups and subgroups within the organization, and additionally yields insight into data with practical applications in the areas of succession planning and employee retention vis-à-vis members of the emerging millennial leadership cohort. Lessons from applications of social identity theory to OI were drawn upon for analysis of the archival and interview data gathered for the study.

\section{Review of the Literature}

\subsection{Researching Organizational Identity}

Sato (2014) framed the study of OI as encompassing two broad categories: research which aims to identify and describe a particular organization's identity, and research which aims to uncover how OI affects organizations. Greater or lesser examples of identity elasticity can come into play depending on organizational stability and internal and external agents weighing on individual perceptions of OI. As the study of OI has evolved, an additional trend has been the adoption of more process-based and temporally informed views about its nature, supporting a growing recognition any organization's identity is always a work in progress (Sato, 2014). The literature points to organizational documents such as catalogs and publications as potential sources of identity claims. The intrinsic case study conducted at MDC presented an opportunity to examine OI processes over the entire life of an organization, potentially identifying transformational moments as well as moments when institutional players labored to preserve a core identity amid internal and external oppositional forces. 


\subsection{Organizational Image and OI}

The dichotomy between internal and external stakeholder perceptions, expressed in the literature as the dividing line between OI and organizational image, may not be entirely well defined. While image has been used to describe the overall impression of an organization, and scholars have mainly focused on organizational image as it is perceived by external audiences, its perception by internal stakeholders has been shown to exert an impact on employees' motivation, work behaviors, and job performance (Rho, Yun, \& Lee, 2015). A study of 1,220 public sector employees in Georgia and Illinois explored the gray area between internal and external stakeholder perceptions of organizational image (Rho et al., 2015). The researchers hypothesized: (a) perceived OI is positively associated with a member's organizational identification, (b) an organization's construed external image is similarly associated with a member's organizational identification, and (c) the intensity of a member's identification with the organization is positively associated with extra-role behavior. A survey of the study participants included questions about organizational quality and performance from two different viewpoints: employees' perceptions and employees' beliefs about how outsiders view the organization. Results of quantitative analysis of the survey results revealed positive correlations between individual perceptions of well-managed OI and image, and high levels of employee identification with the organization, with positive outcomes on factors such as absenteeism (Rho et al., 2015).

Social media platforms are increasingly used by organizations to expose OI elements to constituents, thereby exploiting a highly dynamic medium to develop and shape organizational image (Syrdal \& Briggs, 2016). The technology's increasing pervasiveness is an opportunity for public sector organizations to accomplish the crucial tasks of enhancing the organization's image, soliciting donations, and stimulating consumption of the intangible products and services provided by public entities such as higher education institutions (Syrdal \& Briggs, 2016). Syrdal and Briggs (2016) investigated engagement with a nonprofit animal welfare organization's social media presence, and found engagement to be related to positive word of mouth and higher levels of satisfaction among stakeholders. The researchers created a conceptual model of the organization's social media presence and examined whether: (a) brand loyalty is positively related to interactions with social media, (b) content authenticity is positively related to interactions with social media content, and (c) interaction with social media content is positively connected to positive organizational image. Data from an online survey of the organization's social media constituents affirmed positive relations between a highly developed social media presence and brand attachment, content authenticity, and positive organizational image.

\subsection{Organizational Memory and OI}

The transmission of OI across generational cohorts may be understood as a function of organizational memory. OI is related to the concept of organizational memory, but also distinct. Important and foundational events can have impacts which determine the shape and influence of organizational memory across years and even decades. A study of the policy aftereffects after the U.S. Air Force's overwhelming success during Operation Desert Storm in 1991, where massive air support played a decisive role in the outcome of the war, revealed the emergence of a set of ingrained symmetrical practices across the tactical and operational levels of the entire military establishment, which were not always a correct fit for more recent challenges against foes employing asymmetrical tactics (Brown, 2016). In subsequent conflicts, theaters of war such as Iraq spiraled into chaos following the conventional war-fighting phase because of organizational forgetting or incomplete remembering of key counterinsurgency measures. During the second Gulf War, the U.S. military found its institutional memory, in the form of COIN (an abbreviation for counterinsurgency) was insufficient for the challenges of the new engagement (Brown, 2016).

While the idea of organizational memory can have generally positive connotations, ingrained organizational memories can exert undue influence on decision makers and spur actions which, while correct in the past, do not fit current circumstances (Brown, 2016). On the other hand, organizational forgetting, which might be viewed at times as a negative phenomenon, is a set of actions organizations use as self-protection against organizational memories and behavioral patterns which are no longer practical or suitable for organizations (Brown, 2016). Organizations can generate knowledge, retain the knowledge, and disseminate it across the ranks and to new generations of workers. Organizations are also able to forget knowledge, through unintentional and intentional mechanisms (Brown, 2016). Results from a study of organizational forgetting in two management coaching companies revealed the inherent knowledge structures of organizations can have varied effects on organizational forgetting (Brown, 2016).

\subsection{Organizational Archives and OI}

Organizations and individuals generate document trails which are the basis of archival collections (Gilliland, 2014). Whether created originally as paper documents or born digital, the transformation of textual artifacts into easily searchable digital objects provides opportunities for researchers to mine, forensically analyze, cross-compile, augment, and otherwise search or map these records for the benefit of host organizations and the academy (Gilliland, 2014). 
The extent to which institutional archives provide these benefits is a function of historical completeness, or at least of an ability to provide a representative image of organizational operations, decision-making, administrative processes, and identity (Gilliland, 2014). Ocasio, Mauskapf, and Steele (2016) placed archival repositories at the center of a knowledge management workflow which influences the sustainability of organizational memory. Specific memory objects gain importance and endurance through intentional acts of selection and preservation. The organizational act of establishing archives and providing for retrieval of memory objects shapes individuals' understandings of past occurrences and influences future actions (Ocasio et al., 2016). Specifically, this type of institutionalized organizational remembering begins with the retrieval process, encompassing the discovery, recollection, and reinterpretation of archived documents, along with the ideas and claims represented (Ocasio et al., 2016).

In a comparative case study of national postal services, researchers found a recognition at the highest management levels in the Estonian postal service of the need for records and document management, in contrast with record-keeping practices in the New Zealand post, which were insufficiently embedded to survive organizational change (Gilliland, 2014). Researchers compiled historical records of the postal services in each of the subject countries to prepare a comparative analysis of record-keeping practices. A complex collection of cultural and political forces combined in each case to produce the contrasting outcomes. Such examinations of social and political culture and intentionality in the development and maintenance of institutional archives and the impact of archival holdings on the sustainability of OI weigh on the research study.

\subsection{Academic Institutions and OI}

Higher education institutions are underrepresented in the OI literature; however, one might bring certain assumptions to the table based on stereotypical portrayals of the academic environment, in which the desires of administration are often at odds with those of the faculty. In a qualitative analysis of OI perceptions among faculty at Mersin University in Turkey, Gizir (2014) found expected categories of perception of OI, such as: ineffective administrators, lack of policy, and nonparticipative decision-making processes; but also belonging, loyalty, and organizational image. In other studies, higher education institutions have been found to display dynamic organizational identities in response to the requirements of faculty members, local and state governments, students, and other stakeholders (Barraquier, 2013; Stensaker, 2015). These studies were applicable and may serve as a base to expand on prior research on OI sustainability as it pertains to similar institutions.

Community colleges face challenges to traditional identity, and what literature exists specifically addresses the identity issues of these organizations portrays a state of flux. Stensaker (2015) proposed a tweak of community college culture, which retains teaching as the primary role of faculty members, but adds an emphasis on scholarship focused on the development and refinement of pedagogical practice. A shift in OI for community colleges, which addresses the diffident professional identity of community college faculty, constitutes a step in strengthening these institutions (Stensaker, 2015).

\section{Methods and Procedures}

\subsection{Research Questions}

The following research questions guided the qualitative intrinsic case study:

Research Question 1: What can institutional archives reveal about the development of organizational identity (OI)?

Research Question 2: What are the intentional or unintentional actions taken by the community college's leaders which shaped its OI?

Research Question 3: What processes affected the evolution of organizational memory?

Research Question 4: What is the impact of generational membership on OI?

\subsection{Population and Sample}

The sample $(n=30)$ for the semi structured interviews of millennial generation emerging leaders was randomly selected from a population determined by criteria in Table 1 with assistance from the HR department of MDC. A letter of support and approval was obtained from the institution's HR department. After approval of the study by MDC's Institutional Review Board, the sample requirements were presented to the HR department with the parameters as shown in Table 1. 
Table 1. Sample Requirements

\begin{tabular}{ll}
\hline Requirement & Description \\
\hline Age & Members of the millennial generational cohort of persons born between 1981 \\
and 1997 (Fry, 2015). \\
Organizational rank & $\begin{array}{l}\text { Members of the managerial class of employees, designated at Miami Dade } \\
\text { College as Professional Exempt Contractual, without regard to specific } \\
\text { departments (Miami Dade College, 2017). }\end{array}$ \\
& $\begin{array}{l}\text { Persons who have passed the 90-day probationary period of employment and } \\
\text { Tenure } \\
\text { have completed orientation sessions and onboard training (Miami-Dade } \\
\text { Community College, 1988). }\end{array}$ \\
\hline
\end{tabular}

Table 2 provides a breakdown of the employee tenure at MDC as of December 2015, as measured by years of full-time service to the institution. Approximately $75 \%$ of all full-time employees and $77 \%$ of other full-time employees of MDC, the latter of which includes the administrative class being studied, have served at the institution for 15 years or less (MDC, 2016). For employees whose only work experience has been at MDC, this length of employment would be typical of millennial generation workers, given millennials are understood to have begun entering the workforce at the turn of the 21 st century.

Table 2. Employee Tenure, Miami Dade College

\begin{tabular}{llll}
\hline Years of service & $\begin{array}{l}\text { Full-time } \\
\text { faculty }^{\mathrm{a}}\end{array}$ & $\begin{array}{l}\text { Other }^{\mathrm{b}} \\
\text { full-time } \\
\text { employees }\end{array}$ & $\begin{array}{l}\text { All }^{\mathrm{c}} \\
\text { full-time } \\
\text { employees }\end{array}$ \\
\hline$<6$ & $31 \%$ & $45 \%$ & $41 \%$ \\
$6-10$ & $18 \%$ & $16 \%$ & $17 \%$ \\
$11-15$ & $20 \%$ & $16 \%$ & $17 \%$ \\
$16-20$ & $6 \%$ & $8 \%$ & $8 \%$ \\
$21-25$ & $12 \%$ & $6 \%$ & $8 \%$ \\
26 or more & $12 \%$ & $9 \%$ & $10 \%$ \\
Total & $100 \%$ & $100 \%$ & $100 \%$ \\
\hline
\end{tabular}

\subsection{Instrumentation}

Semi structured interviews were conducted to obtain data about perceptions of OI from administrative personnel who are members of the millennial generation. The interviews were primary qualitative data collection tool used to gather evidence related to Research Questions Three and Four: What processes affected the evolution of organizational memory? What is the impact of generational membership on OI? These semi structured interviews were conducted with 30 MDC participants, who are working as managers and/or supervisors without regard to specific departments, and whose ages fall within the range for membership in the millennial generation: people born between 1981 and 1997. The interview questions were designed to obtain interviewee perceptions with respect to OI as presented by Albert and Whetten (1985), whose formulation of the OI construct comprised the lasting, distinct, and central expression understood by an organization's members to answer questions about corporate character, activities, and aspirations (Albert \& Whetten, 1985).

\subsection{Data Collection}

Archival data was collected through retrieval of documents from the MDC archives. Several document sets, which weigh upon the research questions, were collected and incorporated into the data set for the study, including agenda items and minutes from the meetings of the institution's board of trustees; various white papers, self-study reports, and accreditation documents; course catalogs, which include narrative elements detailing college policies and procedures; and local news stories about the institution. A process of reading and coding of the archival documents took place during the three months it took to complete the thematic analysis. The documents provided data on the origins and evolution of OI and community perceptions of the institution. Document data was gathered through database searches followed by retrieval of digitized documents, and digitization of selected paper documents. The initial criterion for the selection of documents was the potential of containing information pertinent to the analysis of OI at the institution; in 
other words, whether the documents could contain the institution's answers to the questions of who it was, what it was doing, and what it wanted for the future (Albert \& Whetten, 1985).

Upon definition, sizing, selection, and sourcing of the interview sample and approval of the research proposal, $30 \mathrm{semi}$ structured interviews of persons who are working as managers and/or supervisors without regard to specific departments who are members of the millennial generational cohort were conducted via telephone over a period of three weeks. These participants were not selected based on membership in particular departments at the institution, but solely on status as memberships of the emerging leadership class.

The participants came from a pool of millennial generation managerial and/or supervisory employees as identified by MDC's HR department. Telephone interviews for the qualitative intrinsic case study ensured easier access to participants, given the large geographical area covered by the institution, and a need to make the interview as unobtrusive and convenient with respect to work schedules.

The main part of the interview probed for interviewee perceptions related to OI as formulated by Albert and Whetten (1985). Flexibility was allowed to ask additional questions for follow-up or clarification, or to pose the questions in ways which were more understandable as warranted by circumstances. The interviews were recorded with permission of the participants. The recordings were transcribed for importation into the ATLAS.ti CAQDAS software.

\subsection{Data Analysis}

The four research questions were developed to address a research gap in the OI literature regarding generational change in higher education institutions, focusing on community colleges. The special nature of the subject institution, including its size and integration with the community, informed components of the study. The subject institution's multigenerational managerial workforce informed components of the study related to the effects of generational membership.

\section{Research Question One}

Research Question One asked, What can institutional archives reveal about the development of organizational identity (OI)? The results indicated institutional archives, when studied systematically, can reveal the important components of an organization's identity narrative as stored in its recorded processes. The factors determining how detailed this narrative can be include the nature of the documents which can be collected, the time period covered by the archives, the extent to which the documents have been digitized and are therefore easily searchable, and the level of access permitted to the documents.

Nature of the documents. The MDC archives was established in 2005 in order to collect and maintain records of enduring value created or received by the College and its employees (MDC, 2013). With a collection comprising thousands of records of important administrative meetings, books, pamphlets, audiovisual objects, and reports, MDC has taken steps to ensure future scholars can reconstruct the institution's history with useful levels of detail. The extraction of 10 OI-related themes from document analysis of the Board of Trustees meeting records and other documents points to the applicability of such document collections in OI research.

Time period. The MDC archives collections contain documents dating from the earliest days of the institution's founding, in 1960, through the present. This substantial chronological time coverage permitted the analysis of OI development across the institution's entire history. Archival documents demonstrated functionality as enduring records of the thoughts and feelings of institutional actors who are no longer living.

Digitization of the documents. A digitization program begun at the time of the founding of the MDC archives in 2005 led to the creation of thousands of digitized information assets. These assets included much of the document base used in the study. Digitized historical documents facilitated the work performed with Computer Assisted Qualitative Data Analysis (CAQDAS) and made possible the extraction and correlation of themes. Digitization was therefore demonstrated to be an important and investment-worthy enhancement to archival document collections in studying the emergence and evolution of OI.

Access to the documents. Archives can yield information in direct proportion to the level of access granted to researchers. MDC's archives collection contains documents which are considered public records, removing barriers to access and use for research purposes. The researcher was granted essentially unfettered access to the collection; researchers at institutions where access is not as readily forthcoming could experience greater difficulty in constructing a coherent picture of OI development.

\section{Research Question Two}

Research Question Two asked, What are the intentional or unintentional actions taken by the community college's leaders which shaped its OI? 
The analysis of archival documents and interviews of millennial generation managers to identify key OI-related themes provided a window into the ways in which the subject institution's identity may have been shaped by key administrative actions. Examination of key actions by the Boards of Trustees and the College Presidents reveal explicit moments of OI creation, in which the contours of the institution's identity were shaped by the decisions made and enacted. Archival documents reveal a range of intentional actions which shaped the dimensions of OI related to open access/open admissions, opportunity, and diversity, including:

- The racial desegregation of the first campus in the early $1960 \mathrm{~s}$;

- The adoption of, and compliance with, federal civil rights and equal opportunity legislation in the 1960s and 1970s;

- The development of special programs geared toward Cuban and Haitian refugees in the 1970s and 1980s;

- Mobilizations of the community with campaigns to maintain open access throughout the institution's history; and

- The introduction of low-cost, high-quality bachelor's degree programs aimed at areas of critical need, such as exceptional education and nursing, in the early 2000s.

Similarly, emergent OI themes connected with technology and data focus can be traced to strategic organizational decisions to implement various large-scale administrative computing systems, culminating with the MDConnect ERP system in the 2010s. Finally, throughout the institution's history, conscious administrative decisions to keep tuition costs low and academic standards high bolstered MDC's identity as a provider of relatively inexpensive and highquality education.

A lack of intentionality in actions which shaped OI was difficult to discern. There may have been unintended effects on OI from certain intentional administrative actions. For example, the institution's ongoing pursuit of open access and open admissions for the widest possible variety and number of students produced the unintentional effects, described by millennial managers, of large numbers of students straining resources and service capacities, and of students being overwhelmed or discouraged by bureaucratic hurdles. The outcome with respect to OI was a negative effect on the identity element representing relations with and service to students. Millennial managers expressed feelings the introduction of new administrative technology systems, while creating new efficiencies, also may have shifted the institution's focus to a colder, more data-driven approach toward provision of student services.

\section{Research Question Three}

Research Question Three asked, What processes affected the evolution of organizational memory? Processes related to the evolution of organizational of organizational memory involved intentional actions by MDC's administration to memorialize events or elevate assigned levels of importance to the point of granting status as key elements of MDC's rhetorical history. The ceremony and ritual theme derived from analysis of archival documents exemplifies this OI component, with actions such as proclamations, groundbreakings, dedications, and anniversary celebrations marking moments of organizational memory creation and reinforcement. Artifacts from these intentional memory-creation acts have been collected at the MDC archives, the establishment of which, in 2005, also represented an intentional act of organizational memory preservation.

Intentional acts or creations of ceremony and ritual were found to have a reduced, or even fading importance to the millennial managers. Questions aimed at eliciting responses related to this theme generated no data, implying a greatly reduced sense of importance for this expression of OI among millennial cohort. Thus, an institutional consciousness about the importance of the college's history in the community may be reemerging in the form of an alumni fundraising campaign titled "I AM MDC." Beginning in 2017, the college's alumni affairs department established the date of September 6 (the day in 1960 on which the college first opened to students) as "I AM MDC" Day. For the inaugural fundraising event in 2017, historical pictorial elements, such as the first student services building, were used to evoke the institution's history and appeal to donors. The pursuit of financial and political support from the community, therefore, may be another process which drives the creation and preservation of organizational memory.

\section{Research Question Four}

Research Question Four asked, What is the impact of generational membership on OI? The literature provides a complex picture of the millennial generation, with stereotypical portrayals in the culture at large not necessarily supported by research studies. Though popular media accounts have stereotyped millennials as being self-absorbed and pampered, research indicates these characterizations may be oversimplifications, and the generational cohort is a complex group which resists one-size-fits-all categorization. The analysis of interviews of millennial generation managers at MDC indicated a strong commitment to the core themes of OI which developed over the institution's history, including: academic excellence, open access, assistance to the underprivileged, and community service. Some emerging expressions of OI depart from those found in the analysis of archival documents and may be indicative of the millennial generation's perspectives and challenges. These include: 
- An acute sensitivity to the ever-increasing costs of higher education and the enormous value of a combined low-cost, high-quality offering as offered at MDC;

- An innate understanding of the power of data analysis and its uses in the daily work of an educational institution;

- A deep desire to work in a culturally diverse setting amid a polarized national cultural milieu;

- An aversion to hierarchical organizational structures and unnecessary bureaucratic complexity;

- A need for highly collaborative work environments, typified by efficient teamwork and a minimum of political infighting or rivalry;

- A desire for and sense of pride in meaningful work which provides social and professional opportunities to underserved and underprivileged persons;

- A need to feel the organization is investing in individuals, through well-designed professional development programs; and

- A desire to develop and work with cutting-edge administrative and academic technologies for delivering high-quality experiences to students.

\section{Discussion and Conclusions}

Organizational identity (OI) is defined as the lasting, distinct, and central expression understood by an organization's members to answer questions about corporate character, activities, and aspirations (Albert \& Whetten, 1985). The study examined perceived generational differences in the sustainability of (OI) which need to be identified and better understood. As educational organizations grow and change, succeeding leadership cohorts may become disconnected from original elements of OI, with implications for succession planning. The study advances general knowledge about OI in educational organizations, and potentially informs strategies for addressing the emerging administrative cohort's knowledge gap regarding the sustainability of institutional OI. The study also contributes to the subject institution's strategic planning process.

Data analysis of over 3,000 digitized archival documents and 30 transcripts of interviews with millennial generation managers was performed to address the research questions. Ten core OI related themes were revealed during the analysis of archival documents (see Table 3).

Table 3. 10 Core Themes OI Themes Derived From Archival Documents

\begin{tabular}{|l|l|}
\hline Themes & Explanation of Theme \\
\hline Academic Excellence & $\begin{array}{l}\text { The college strives to provide a high-quality education for both the } \\
\text { neediest students and the best students. }\end{array}$ \\
\hline Aggressive Campus Building Projects & $\begin{array}{l}\text { The college pursues large-scale building projects in order to serve } \\
\text { its rapidly growing student population, with a focus on building } \\
\text { campuses and buildings undeveloped, underdeveloped, or } \\
\text { declining parts of the community. }\end{array}$ \\
\hline Assistance to the Underprivileged & $\begin{array}{l}\text { The college works ensure access to education for underprivileged } \\
\text { persons through programs to address social and financial obstacles } \\
\text { to success. }\end{array}$ \\
\hline Ceremony and Ritual & $\begin{array}{l}\text { A great emphasis is placed on ceremonies and ritual actions to } \\
\text { memorialize important events. }\end{array}$ \\
\hline Community Service & $\begin{array}{l}\text { The college creates programs which function in tandem with } \\
\text { community social programs, in order to address social problems, } \\
\text { which interfere with education. }\end{array}$ \\
\hline Financial Management and Stability & $\begin{array}{l}\text { The college creates programs which function in tandem with } \\
\text { community social programs, in order to address social problems, } \\
\text { which interfere with education. }\end{array}$ \\
\hline Open Access/Open Admissions & $\begin{array}{l}\text { The college has continually endeavored to "keep the doors open" } \\
\text { and provide open access to tertiary education. }\end{array}$ \\
\hline Promoting Arts and Culture & $\begin{array}{l}\text { The college actively promotes the development of arts and culture } \\
\text { in the community. }\end{array}$ \\
\hline Relations with Students & $\begin{array}{l}\text { The college fosters a student-focused environment, with less } \\
\text { emphasis on research and more emphasis on teaching and } \\
\text { learning. }\end{array}$ \\
\hline Vocational Education & $\begin{array}{l}\text { The college is at the forefront of workplace education and } \\
\text { provides shorter-term alternatives to students seeking vocational } \\
\text { training. }\end{array}$ \\
\hline
\end{tabular}


The analysis of interview transcripts of millennial managers revealed the presence of most of the themes found in the archival documents, along with the emergence of eight additional themes. The results indicate institutional archives, when studied systematically, can reveal the important components of an organization's identity narrative as stored in its recorded processes. The analysis of archival documents and interviews of millennial generation managers to identify key OI-related themes provided a window into the ways in which the subject institution's identity may have been shaped by key administrative actions.

Processes related to the evolution of organizational memory were found to involve intentional actions by MDC's administration to memorialize events or elevate perceived levels of importance to the point of granting status as key elements of MDC's rhetorical history. The analysis of interviews of millennial generation managers at MDC indicated a strong commitment to core OI themes which developed over the institution's history, as well as some emerging expressions of OI which depart from those found in the analysis of archival documents and may be indicative of the cohort's perspective.

Given the highly dynamic nature of the sector, more studies about OI in higher education are warranted. The enormous pressures facing the higher education sector in the 21st century will affect OI, with implications for the study of strategic planning and management. With more institutional archives becoming digitized and made available online, comparative OI studies of this type are an exciting possibility for the future. Society is asking more of community colleges, including an expanding role in workforce education and as a potentially free guarantor of higher education to all citizens. Research on OI in community colleges can reveal important trends for management and staffing as the millennial generation takes the reins of tertiary institutions in the coming decades.

\section{References}

Albert, S., \& Whetten, D. (1985). Organizational identity. In L. L. Cummings \& B. M. Staw (Eds.), Research in organizationa lbehavior(263-295).Retrievedfromhttp://psycnet.apa.org/psycinfo/1986-02640-001

Barraquier, A. (2013). A group identity analysis of organizations and their stakeholders: Porosity of identity and mobility of attributes. Journal of Business Ethics, 115(1), 45-62. https://doi.org/10.1007/s10551-012-1363-x

Brown, D. J. (2016). Institutional memory and the US Air Force. Air \& Space Power Journal, 30(2), 38-48. Retrieved fromhttp://www.airuniversity.af.mil/Portals/10/ASPJ/journals/Volume-30_Issue-2/F-Brown.pdf

Chase-Mayoral, A. M. (2017). The global rise of the U.S. community college model. New Directions for Community Colleges,2017(177), 7-15. https://doi.org/10.1002/cc.20237

Cohen, A. M., \& Brawer, F. B. (2013). The American Community College (6th ed.). San Francisco, CA: Jossey-Bass.

Fry, R. (2015). Millennials surpass Gen Xers as the largest generation in U.S. labor force [Website]. Retrieved from http://www.pewresearch.org/fact-tank/2015/05/11/millennials-surpass-gen-xers-as-the-largest-generation-in-us-labor-force/

Gilliland, A. J. (2014). Reconceptualizing records: The archive and archival roles and requirements in a networked society. Knygotyra, 63(1), 17-34. Retrieved from https://www.vu.lt/leidyba/lt/component/k2/item/4310reconceptualizing-records-the-archive-and-archival-roles-and-requirements-in-a-networked-society

Gizir, S. (2014). A qualitative case study on the organizational identity of faculty members. Educational Sciences: Theory \& Practice, 14(4), 1309-1325. https://doi.org/10.12738/estp.2014.4.2064

Miami Dade College. (2013, July 16). Policy 01-I-26: College archives and special collections. Retrieved from http://www.mdc.edu/policy/Chapter1/01-I-26.pdf

Miami Dade College. (2016). Miami Dade College fact book. Retrieved from http://www.mdc.edu/ir/Fact Book/EmployCharac.pdf

Ocasio, W., Mauskapf, M., \& Steele, C. W. J. (2016). History, society, and institutions: The role of collective memory in the emergence and evolution of societal logics. Academy of Management Review, 41(4), 676-699. https://doi.org/10.5465/amr.2014.0183

Palmadessa, A. L. (2017). America's college promise: Situating President Obama's initiative in the history of federal higher education aid and access policy. Community College Review, 45(1), 52-70. https://doi.org/10.1177/0091552116673710

Ravasi, D. (2016). Organizational identity, culture, and image. In M. G. Pratt, M. Schultz, B. E. Ashforth, \& D. Ravasi (Eds.), The Oxford handbook of organizational identity (pp. 65-77). https://doi.org/10.1093/oxfordhb/9780199689576.013.25

Rho, E., Yun, T., \& Lee, K. (2015). Does organizational image matter? Image, identification, and employee behaviors in public and nonprofit organizations. Public Administration Review, 75(3), 421-431.

https://doi.org/10.1111/puar.12338 
Sato, H. (2014). How do we understand organizational identity effect? Annals of Business Administrative Science, 13(5), 271-281. https://doi.org/10.7880/abas.13.271

Stensaker, B. (2015). Organizational identity as a concept for understanding university dynamics. Higher Education, 69(1), 103-115. https://doi.org/10.1007/s10734-014-9763-8

Syrdal, H. A., \& Briggs, E. (2016). Developing a positive organizational image: The role of engagement with social media content. In J. G. Fowler \& J. Weiser (Eds.),Society for Marketing Advances Proceedings (pp. 74-84).

Retrieved from http://c.ymcdn.com/sites/www.marketingadvances.org/resource/resmgr/Proceedings/SMA2016_v11.pdf\#page=74

Tajfel, H., \& Turner, J. C. (1986). The social identity theory of intergroup behavior. In S. Worchel \& W. G. Austin (Eds.), Psychology of intergroup relations (pp. 7-24).

https://doi.org/http://doi.org/10.1111/j.1751-9004.2007.00066.x 